\title{
Integrative review: concepts and methods used in nursing
}

\author{
REVISÃO INTEGRATIVA: CONCEITOS E MÉTODOS UTILIZADOS NA ENFERMAGEM \\ REVISIÓN INTEGRADORA: CONCEPTOS Y MÉTODOS UTILIZADOS EN ENFERMERÍA
}

\author{
Cassia Baldini Soares ${ }^{1}$, Luiza Akiko Komura Hoga ${ }^{2}$, Marina Peduzzi ${ }^{3}$, Carine Sangaleti ${ }^{4}$, Tatiana \\ Yonekura ${ }^{5}$, Deborah Rachel Audebert Delage Silva ${ }^{6}$
}

\begin{abstract}
Integrative review (IR) has an international reputation in nursing research and evidence-based practice. This IR aimed at identifying and analyzing the concepts and methods recommended to undertaking IR in nursing. Nine information resources, including electronic databases and grey literature were searched. Seventeen studies were included. The results indicate that: primary studies were mostly from USA; it is possible to have several research questions or hypotheses and include primary studies in the review from different theoretical and methodological approaches; it is a type of review that can go beyond the analysis and synthesis of findings from primary studies allowing exploiting other research dimensions, and that presents potentialities for the development of new theories and new problems for research. Conclusion: IR is understood as a very complex type of review and it is expected to be developed using standardized and systematic methods to ensure the required rigor of scientific research and therefore the legitimacy of the established evidence.
\end{abstract}

\section{DESCRIPTORS}

Review

Measurements, methods and theories

Nursing care

Evidence-based practice

Nursing research

\section{RESUMO}

A revisão integrativa (RI) apresenta reputação internacional na pesquisa em enfermagem e na prática baseada em evidências. Esta RI objetivou identificar e analisar conceitos e métodos indicados para desenvolver uma RI na enfermagem. Nove recursos informacionais bibliográficos, incluindo fontes de literatura cinzenta, foram consultados. Dezessete estudos foram incluídos. Os resultados indicam que os estudos foram desenvolvidos majoritariamente nos EUA; é possível ter várias questões de pesquisa ou hipóteses e incluir investigações desenvolvidas através de diferentes referenciais teóricos e metodológicos; trata-se de um tipo de revisão que permite realizar análises que extrapolam a síntese dos resultados dos estudos primários, abrangendo outras dimensões da pesquisa e que apresenta potencialidade para o desenvolvimento de novas teorias e problemas de pesquisa. Em conclusão, a RI é compreendida como um tipo de revisão de natureza complexa, que demanda métodos normatizados e sistemáticos para garantir o necessário rigor requerido na pesquisa científica e a legitimidade das evidências estabelecidas.

\section{DESCRITORES}

Revisão

Medidas, métodos e teorias

Cuidados de enfermagem

Prática clínica baseada em evidências

Pesquisa em enfermagem

\section{RESUMEN}

La Revisión Integradora (RI) tiene una reputación internacional en la investigación en enfermería y en la práctica basada en la evidencia. Esta RI tuvo como objetivo identificar y analizar los conceptos y los métodos indicados para la realización de una RI en enfermería. Fueron consultados nueve recursos de información y fuentes de literatura gris. Se incluyeron diecisiete estudios de RI. Los resultados indican que: la mayoría de los estudios primarios fueron realizados en EE.UU.; es posible tener varias preguntas de investigación o hipótesis e incluir estudios primarios de diferentes perspectivas teóricas y metodologías; es un tipo de análisis que puede ir más allá de la síntesis de las conclusiones de los estudios primarios, permitiendo abarcar otras dimensiones de la investigación y finalmente presenta potencial para el desarrollo de nuevas teorías y problemas de investigación. En conclusión, la RI es comprendida como un tipo de revisión de naturaleza compleja que demanda métodos normalizados y sistemáticos para garantizar el rigor requerido en la investigación científica y por lo tanto la legitimidad de las evidencias establecidas.

\section{DESCRIPTORES}

Revisión

Mediciones, métodos y teorías

Atención de enfermería

Práctica clínica basada en la videncia

Investigación en enfermería

\footnotetext{
${ }^{1}$ Associate Professor, Department of Collective Health Nursing, School of Nursing, University of São Paulo, São Paulo, SP, Brazil. cassiaso@usp.br ${ }^{2}$ Associate Professor, Department of Maternal-Child and Psychiatric Nusing, School of Nursing, University of São Paulo, São Paulo, SP, Brazil. ${ }^{3}$ Associate Professor, Department of Profissional Guidance, School of Nursing, University of São Paulo, São Paulo, SP, Brazil. ${ }^{4}$ Assistant Professor, Universidade Estadual do Centro-Oeste, Guarapuava, PR, Brazil. ${ }^{5}$ PhD Student, Department of Collective Health Nursing, School of Nursing, University of São Paulo, São Paulo, SP, Brazil ${ }^{6}$ PhD Student, Department of Maternal-Child Health, College of Public Health, University of São Paulo, São Paulo, SP, Brazil.
} 


\section{INTRODUCTION}

Various terms are used in regard to scientific literature reviews. Terms for studies that synthesize findings regarding a specific phenomenon investigated in preliminary studies include integrative, traditional, narrative, and systematic reviews, meta-analysis, meta-synthesis, and meta-summaries, among others. A study presented 14 terms that describe different concepts and strategies of literature review ${ }^{(1)}$, referring to a general form of searching, selecting, and analyzing publications on a specific topic.

In the last decade, the term integrative review (IR) and studies that use this method have increased considerably in the field of nursing, which is associated with the increasing trend in the field to identify individual and collective health care as a complex work that requires collaboration and integration of knowledge from diverse subjects ${ }^{(2)}$. This trend is observed in the field of evidence-based health care, or evidence-based practice, and it is recognized that the combination of research methods from different epistemological matrixes can provide results that benefit nursing care $^{(3-4)}$.

In order to respond to the needs of individual or collective care, the production of knowledge in nursing needs to be broad and manifold. Different paradigms that orient research in nursing are capable of producing knowledge from different perspectives of care. The integration of these perspectives, however, requires rigorous methods ${ }^{(5)}$.

Following this trend, the idea that literature reviews also have the potential to synthesize findings from research that uses different methods in the same study, or different studies of the same topic that use different quantitative or qualitative methods, has been proposed. Nevertheless, there is currently no consensus on how to best integrate the results, nor on the theoretical-methodological challenge of integrating results of studies structured in different ways and founded on different paradigms ${ }^{(1)}$.

Using the sources Medline and Lilacs, one review performed in 2010 analyzed five scientific articles, which all conceptualized the IR, and defined its stages. The study concluded that IR is a tool that synthesizes findings from different research frameworks, and that requires rigorous systematics in data analysis ${ }^{(6)}$.

$I R$, therefore, is a type of literature review that brings together findings from different methodologies, thereby facilitating the reviewer to synthesize findings without harming his/her epistemological filiation. In order to achieve this purpose without making epistemological nonsense, IR requires rigorous stages of analysis and synthesis.

This study was performed aiming at reaching answers to the following question: what does nursing literature say about the concepts and methods of integrative reviews? Thus, the aim of this study was to identify and analyze the concepts and methods recommended for IR in nursing literature.

\section{METHOD}

This study on IR was developed according to the recommendations proposed by two North-American researchers ${ }^{(7)}$, whose study was included among the primary studies of this review. The review was restricted to studies regarding the theories and methodologies of IRs (concept, criteria of rigor, stages, and instruments) used in nursing. Quantitative or qualitative theoretical-methodological studies that analyzed or proposed a theory and/ or methodology of IR were included, whereas primary studies that used IR as a methodology to review an object of research were excluded. There were no limitations in regards to the date of publication, or language restrictions for preliminary studies.

The studies were sought in nine information sources, including five electronic databases (BDEnf, CINAHL, LILACS, SCOPUS and Web of Sciences), the PubMed portal, which comprises MEDLINE, two digital libraries (the thesis database of the Brazilian Federal Agency for Support and Evaluation of Graduate Education and SciELO), and one academic web search engine (Google Scholar) were used. Thus, in addition to the database for indexed scientific publications, grey literature sources were also used, which includes unpublished literature, such as conference abstracts and technical documents. The search was improved by conducting a manual search of the citations of the identified preliminary studies. The term Integrative Review, in English or Portuguese, in the title, abstract, or issue, depending on the database, was used to locate the studies. The search was performed in March 2013.

After identification of all studies, analysis was done to select those for the IR, according to the study-guiding question and the inclusion criteria cited above. All of the studies identified through the search were initially evaluated by their titles and abstracts. In cases where the titles and abstracts were not sufficient to make an initial selection, the entire article was reviewed.

A research instrument was developed for the extraction and analysis of data from the selected studies. The instrument responded to the following questions: (1) Does the text differentiate IR from other types of review? If yes, how so? (2) Which concept is used? Definition of the concept (describe its elements); (3) What are the criteria of rigor for an IR? (methodological structuring); (4) Stages how to perform the IR; and (5) Recommendations of criteria for the checklist. This stage was performed by two independent groups of reviewers.

\section{RESULTS}

The search identified 3994 references, 3978 of which were identified through the databases, whereas 16 were identified through grey literature and manual searches. 
Selection by title and abstract resulted in 47 references, from which 22 duplicate references were removed. Following evaluation of the 25 remaining references, eight were excluded, resulting in 17 references being included in this IR. Chart 1 shows the number of references identified and selected by database/source and search strategies, after selection by title and abstract.

Chart 2 shows the references that were excluded and the respective reason for their exclusion.
Thus, 17 studies were included in this review. Chart 3 lists the data regarding the author(s), publication year, country of primary author, field of knowledge of the authors and database from which the publication was retrieved.

Regarding temporal analysis, the studies were published as of the 1980 s, with seven studies (41.2\%) being published after 2000. Most authors of the primary studies were from the USA, with 12 of these references $(70.5 \%)$, and the predominant field of knowledge was nursing (64.7\%).

Chart 1 - Information sources (excluding web search engine), search strategies, and the identified and selected references - São Paulo, 2013

\begin{tabular}{|lllc|}
\hline \multicolumn{1}{|c}{ Database/source } & \multicolumn{1}{c}{ Search strategy } & References found & References selected by title and abstract \\
\hline PubMed & Integrative review[Title/Abstract] & 704 & 3 \\
\hline Web of Sciences & "Integrative Review" & 579 & 7 \\
\hline LILACS & Integrative [words] and review [words] & 274 & 7 \\
\hline SciELO & Revisão [abstract] and Integrativa [abstract] & 221 & 2 \\
\hline SCOPUS & TTITLE-ABS KEY("integrative review") & 1300 & 6 \\
\hline CINAHL & AB Integrative review & 649 & 8 \\
\hline BDENF & Integrative AND Review & 119 & 1 \\
\hline CAPES Thesis database & Revisão integrativa (subject) & 132 & 0 \\
\hline
\end{tabular}

Chart 2 - List of references excluded and reason for exclusion - São Paulo, 2013

\begin{tabular}{|cll|}
\hline $\mathbf{N}$ & \multicolumn{1}{|c|}{ Reference } & Reason \\
\hline 1 & $\begin{array}{l}\text { Griffin RJ. The integrative research review: a systematic approach - Cooper HM. Journal Q. } \\
1985 ; 62(3): 688-689 .\end{array}$ & It was an editorial \\
\hline 2 & $\begin{array}{l}\text { McGrath JM. Systematic and integrative reviews of the literature: how are they changing our } \\
\text { thoughts about practice? J Obstet Gynecol Neonatal Nurs. 2009;38(4):375-376. }\end{array}$ & IR was the study methodology \\
\hline 3 & $\begin{array}{l}\text { Lacerda RA, Nunes BK, Batista Ade O, Egry EY, Graziano KU, Angelo M, Merighi MA, Lopes } \\
\text { NA, Fonseca RM, Castilho V. [Evidence-based practices published in Brazil: identification and } \\
\text { analysis of their types and methodological approaches]. Rev Esc Enferm USP. 2011; 45(3):777-86. }\end{array}$ & Did not respond to review question \\
\hline 4 & $\begin{array}{l}\text { Anthony S, Jack S. Qualitative case study methodology in nursing research: an integrative review. } \\
\text { J Adv Nurs. 2009; 65(6): 1171-81. }\end{array}$ & IR was the study methodology \\
\hline 5 & $\begin{array}{l}\text { Pentland D, Forsyth K, Maciver D, Walsh M, Murray R, Irvine L, Sikora S. Key characteristics } \\
\text { of knowledge transfer and exchange in healthcare: integrative literature review. J Adv Nurs. 2011; }\end{array}$ & IR was the study methodology \\
67(7), 1408-25. & $\begin{array}{l}\text { Souza MT, Silva MD, Carvalho R. Integrative review: What is it? How to do it? Einstein (São } \\
\text { Paulo). 2010;8(1): 102-6. }\end{array}$ & $\begin{array}{l}\text { Literature Review: did not propose } \\
\text { theory or methodology }\end{array}$ \\
\hline 7 & $\begin{array}{l}\text { Smith MC, Stullenbarger E. A prototype for integrative review and meta-analysis of nursing } \\
\text { research. J Adv Nurs. 1991;16:1272-1283. }\end{array}$ & Did not respond to review question \\
\hline 8 & $\begin{array}{l}\text { Crossetti MG. Integrative review of nursing research: scientific rigor required. Rev Gaucha Enferm. It was an editorial } \\
\text { 2012 Jun;33(2):8-9. }\end{array}$ \\
\hline
\end{tabular}

Chart 3 - Authors, publication year, country of primary author, field of knowledge of the authors and database from which the publication was retrieved - São Paulo, 2103

\begin{tabular}{|cccc|}
\hline Author(s)/ year & Country of primary author & Field of knowledge & Database/source \\
\hline $1980^{(8)}$ & USA & Education & $\begin{array}{l}\text { Web of Sciences } \\
\text { Google Scholar }\end{array}$ \\
\hline $1982^{(9)}$ & USA & Psychology & $\begin{array}{c}\text { CINAHL } \\
\text { LILACS }\end{array}$ \\
\hline $1984^{(10)}$ & USA & Psychology & Google Scholar Referência da referência \\
\hline $1987^{(1)}$ & USA & Nursing & $\begin{array}{l}\text { Web of Sciences } \\
\text { Google Scholar }\end{array}$ \\
\hline $1991^{(12)}$ & USA & Education & Google Scholar \\
\hline
\end{tabular}


...Continuation

\begin{tabular}{|cccc|}
\hline Author(s)/ year & Country of primary author & Field of knowledge & Database/source \\
\hline $1993^{(13)}$ & USA & Nursing & Referência da referência \\
\hline $1997^{(14)}$ & Norway & Nursing & CINAHL \\
\hline $1998^{(15)}$ & USA & Nursing & CINAHL \\
\hline $1998^{(16)}$ & USA & Nursing & SCOPUS \\
Google Scholar
\end{tabular}

\section{Synthesis of the data: concepts of IR}

A significant conceptual similarity of IR is observed among the authors, especially in regard to the concepts that were initially suggested for nursing. Nevertheless, as nursing assumed $\mathrm{RI}$ as a useful method to respond to

Chart 4 - Concepts and purposes of IR - São Paulo, 2013 research needs in the field, a refinement of the concepts was observed, mainly towards increasing the scope of the review and explaining the complexity of its purposes.

The authors' concepts of IR are synthesized below, in Chart 4, along with their theoretical frameworks.

\begin{tabular}{|c|c|}
\hline Author(s)/year & \multicolumn{1}{c|}{ Definitions and purposes } \\
\hline $1980^{(8)}$ & $\begin{array}{l}\text { Type of review that intends to make generalizations regarding a specific issue from a group of } \begin{array}{c}\text { Author who have previously } \\
\text { published studies on IR. } \\
\text { studies on the topic of interest. }\end{array} \\
\text { reference }\end{array}$ \\
\hline $1982^{(9)} \quad \begin{array}{l}\text { Resource to synthesize the knowledge accumulated on a specific research topic, and to em- } \\
\text { phasize important research questions that have not been sufficiently answered. Further, there } \\
\text { is clear emphasis on the quantitative dimension, that is, on integrating results from empirical } \\
\text { studies with a quantitative approach. }\end{array}$ \\
\hline $1984^{(10)} \quad \begin{array}{l}\text { Summary of the conclusions of previous research with related or identical hypotheses. Thus, } \\
\text { the purpose of IR is to present the state of knowledge regarding the relationships of interest, } \\
\text { and to highlight important questions that the research needs to broaden. }\end{array}$ \\
\hline $\begin{array}{l}\text { First author to write about IR in the field of nursing, while expanding to other purposes such } \\
\text { as suggestions for new theoretical questions, identification of research gaps, and support for } \\
\text { research on conflicting hypotheses. }\end{array}$ \\
\hline $\begin{array}{l}\text { Empirical research with the purpose to: develop theory, synthesize knowledge, and evaluate } \\
\text { substantive methodological advances, in addition to generalizing inference from the analysis } \\
\text { of empirical studies. IR should follow the same theoretical-methodological rigor required in } \\
\text { traditional empirical research, and its results should enable researchers to access accumulated } \\
\text { knowledge by problematizing a topic of interest. Despite the concern with theory develop- } \\
\text { ment, this author recommends that only empirical studies, and not theoretical, should be } \\
\text { included in the review, clarifying that the theoretical aspects should be included with richness } \\
\text { of details, only while creating the foundation for the topic being researched. }\end{array}$ \\
\hline $1991^{(12)}$ \\
(8,24)
\end{tabular}


Critical summary of studies that have already been performed, thereby facilitating new conclusions. Highlights the need to conduct the review based on a specific research question, the 1993(13) definition of important variables, and the description of how the related variables can be included. Meta-analysis is performed for certain IRs with the conditions necessary to reanalyze the results of the studies together, as a single result, in order to determine the effectiveness of the treatment being studied.

Collection, analysis, and integration of results of separately developed studies, with the
purpose to produce a set, configured as a consistent whole with complete meaning. IR is
thus proposed as a type of research capable of interrelating empirical and theoretical find-
ings, with the purpose of providing more ample understanding on a phenomenon of interest.
Clearly motivated by critical analysis of the process of nursing construction as a science,
and the related process of research development in the field. Distances from others, present-
ing IR as an extremely important tool for nursing. Criticizes IRs that are developed without
theoretical support, and that present merely descriptive products, reiterating the need to
develop IRs based on consistent theoretical bases.

\begin{tabular}{|c|c|c|}
\hline $1998^{(15)}$ & $\begin{array}{l}\text { Systematic analysis and synthesis of research on a specific topic. The synthesis of results of } \\
\text { primary studies reduces uncertainty in regard to recommendations for clinical practice, facilitat- } \\
\text { ing decision-making in everyday practice, and improving the cost-benefit of the interventions. } \\
\text { This is a unique approach in that it proposes the use of IR in everyday clinical practice by a team } \\
\text { of health care professionals. For this purpose, methods such as meta-analyses are unfeasible, } \\
\text { but the inclusion of studies is proposed none-the-less because they are positively evaluated by a } \\
\text { specialist on the matter. }\end{array}$ & (8) \\
\hline $1998^{(16)}$ & $\begin{array}{l}\text { Comprehensive report of the key concepts identified in the studies it analyzes. The analyzed } \\
\text { literature comprises all of the studies with identical or related hypotheses to the review, and } \\
\text { should be as rigorous as the primary studies, with a careful application of evaluation criteria to } \\
\text { minimize the effects of subjectivity. }\end{array}$ & $(10-11)$ \\
\hline $1998^{(17)}$ & $\begin{array}{l}\text { First Brazilian authors in nursing to publish work on IR. It is a method that synthesizes and } \\
\text { groups results on a topic in a systematic and ordered manner, making it possible to identify the } \\
\text { authors that study the theme with more frequency, separate scientific findings from opinions } \\
\text { and ideas, map the current status of an issue, and promote the insertion of knowledge into } \\
\text { professional practice and changes. }\end{array}$ & $(9-11,14)$ \\
\hline $2005^{(18)}$ & $\begin{array}{l}\text { Summarizes the theoretical or empirical literature available to promote comprehensive under- } \\
\text { standing of a specific health problem or phenomenon. Thus, it is possible to include in an IR } \\
\text { primary studies developed through the use of diverse methodologies. By involving different } \\
\text { types of studies, methodologies and theories, IR has the potential to deepen analysis of the } \\
\text { data, which makes the development of IR complex. }\end{array}$ & $(8,13)$ \\
\hline $2005^{(19)}$ & $\begin{array}{l}\text { Research that reviews, critiques, and synthesizes literature on a theme in a comprehensive } \\
\text { manner, and is capable of generating new approaches and perspectives on the topic reviewed. } \\
\text { IR is a sophisticated research methodology that requires complex abilities to understand the } \\
\text { phenomenon researched. An IR has purposes: to synthesize "mature" issues that have already } \\
\text { been broadly debated in the literature; or to synthesize new or emerging issues. In the first case, } \\
\text { IR enables new understandings or even reconceptualizations, whereas in the second case, IR } \\
\text { enables the initial conceptualization and amplified perception of the emerging issue. }\end{array}$ & Não descreveu \\
\hline $2005^{(20)}$ & $\begin{array}{l}\text { A type of review in which previous research is summarized to obtain general conclusions. } \\
\text { The purposes of an IR are: to evaluate the potential of a scientific finding; identify gaps in the } \\
\text { research; construct connections between fields; identify central research questions in a field; } \\
\text { generate new research questions; identify theoretical frameworks; and explore the appropriate- } \\
\text { ness of research methods. }\end{array}$ & $(11,13,25)$ \\
\hline $2005^{(7)}$ & $\begin{array}{l}\text { The broadest method of review, since it allows the simultaneous inclusion of experimental } \\
\text { and non-experimental studies, and understanding of the totality of the phenomenon. IR makes } \\
\text { it possible to combine data extracted from theoretical and empirical literature, to integrate a } \\
\text { vast range of objectives related to the review of a specific topic, to define concepts, review } \\
\text { theories, review findings, and to analyze methodological questions. }\end{array}$ & $(8,10-11,13-14,18)$ \\
\hline $2008^{(21)}$ & $\begin{array}{l}\text { An analysis of studies important to a topic, which supports decision-making and the improve- } \\
\text { ment of clinical practice. It permits general conclusions on a specific topic; allows the synthesis } \\
\text { of various studies, including experimental and quasi-experimental research; is an ample analysis } \\
\text { of the literature; permits the combination of data from theoretical and empirical literature; and } \\
\text { can be used to define concepts, review theories, or for the methodological analysis of studies. } \\
\text { The inclusion of differently designed studies increases the potential of IR to increase the depth } \\
\text { and scope of the conclusions. IR is an incipient research method in Brazilian nursing. }\end{array}$ & $(7,10-11,13,15-18)$ \\
\hline
\end{tabular}


...Continuation

\begin{tabular}{|c|c|}
\hline Author(s)/year & \multicolumn{1}{c|}{$\begin{array}{c}\text { Definitions and purposes } \\
\text { reference }\end{array}$} \\
\hline $2009^{(22)}$ & $\begin{array}{l}\text { Broad review method that permits the inclusion of theoretical and empirical studies with dif- } \\
\text { ferent methodological approaches, with the purpose of synthesizing research on a determined } \\
\text { issue. IR has the aim to obtain a conclusion from the results of studies investigating identical } \\
\text { or similar problems. This conclusion comes to constitute a source of knowledge on a problem, } \\
\text { and is evaluated according to its validity to be transferred to practice. }\end{array}$ \\
\hline $2011^{(23)}$ & $\begin{array}{l}\text { Comprehensive research methodology that allows the review, critique, and synthesis of litera- } \\
\text { ture representative of a topic or issue, and that is capable of generating new approaches and } \\
\text { perspectives on the issue. }\end{array}$ \\
\hline
\end{tabular}

The concepts of meta-analyses, systematic reviews, and qualitative reviews were differentiated from that of IR. Meta-analysis was defined as a method of review that combines the evidence of multiple primary studies through the use of statistical methods, thus guaranteeing objectivity and validity of the results ${ }^{(18)}$. Founded on the concept of the Cochrane Collaboration, systematic review was defined as the method of choice for evidence-based practice, which combines findings from multiple studies focused on a specific problem ${ }^{(18)}$. Review of qualitative studies is presented as a type of review with different approaches differentiated by the methods of analysis and interpretation, with several approaches being used to exemplify the differences ${ }^{(26-30)}$. Meta-summaries on the other hand are descriptive, and produce syntheses from primary qualitative studies. Meta-syntheses, meta-studies, and meta-ethnographies are all reviews that propose the critical analysis of qualitative primary studies, and synthesize the findings into a new theory or general framework for the research topic.

An IR author is expected to be capable of identifying an issue or topic appropriate for review, justifying why IR is the appropriate method to approach the research topic, researching and finding the appropriate literature, analyzing and critiquing the literature, and creating new understandings regarding the issue under review through one or more forms of synthesis ${ }^{(19)}$.

There are three types of IR: methodological (critical review and analyses of designs and methodologies of different studies), theoretical (critical review of theories on a particular topic), and empirical (critical review of quantitative and/or qualitative empirical studies on a particular topic, with analysis of results and relation between variables)(7).

\section{Rigor in the development of IR}

IR requires a standard of excellence in regard to methodological rigor so that its product can contribute significantly to science and clinical practice. The preservation of this standard requires the use of methods that guarantee precise, objective, and complete analysis of the topic under review; theoretical support for the analyses of the results, methods, subjects, and variables of the primary studies; the provision of all information contained in the studies reviewed, and not only primary results; in a way that informs readers without overloading them with unnecessary information.

The following suggested procedures should be developed in a critical manner by the reviewer ${ }^{(11)}$ : Clearly define the question or issue of the IR; state the hypotheses that complement the guiding question of the review; describe, in detail, the selection criteria of the studies to be included in the review; define and describe the characteristics of the articles analyzed, the stage considered to be the core of the IR.

The following aspects should be considered in the development of the IR question: how do the authors define the concept, and what are the different theoretical perspectives that have been used to describe it? What studies have been developed focusing on the theme, and how can this scope be expanded? What are the relationships that have been revealed between the concept studied and other related phenomena? What methodological approaches have been used to study and understand the concept? ${ }^{(13)}$

Four other criteria are suggested to analyze research questions in an IR: the theory that supports the research question; the search for previous reviews on the same issue (in the event that one/some are identified, the researcher should judiciously analyze and critique them); review the primary studies to obtain the most adequate research question; the researcher's intuition, ingenuity, and insights also configure a source of the research question or hypotheses of the $\mathrm{IR}^{(8)}$.

Methodological rigor should permeate all stages of an IR. For instance, in regard to the research question, the reviewer should guarantee the appropriateness of the keywords or concepts, and the methodology used to verify whether the studies selected respond to the research question. Two evaluators are required for the data codification phase, and they should be duly prepared to develop this type of work ${ }^{(13)}$.

The rigor of an IR should be guaranteed through presentation of a coherent conceptual structure of the phenomenon. This implies the need to adopt a theory to serve as the basis to debate the set of competing models or existing points of view on the topic under review ${ }^{(8,19)}$. 
A detailed description of the following items, essential to guarantee rigor in each of the stages of an IR, has been recommended ${ }^{(19)}$ :

- Identification of key words, databases, publication years, references manager and use of conceptual matrix to outline the key concepts on the topic.

- Strategies of analysis, synthesis and presentation of results, primary concepts based on the matrix theory, identification and categorization of the primary ideas and themes, and verification of their validity and authenticity.

- Critical attitude during the entire process, to identify strong and weak points in the literature through careful examination of the primary ideas and their relationships with the topic studied, the origin and history of the is sue, its primary concepts, interactions between these, research methods, and applications of the issue studied.

Transparency in the procedures of identification, inclusion and classification of the articles to be reviewed is a guarantee for rigor in an IR. Below are listed the procedures that require transparency ${ }^{(23)}$ : definition of the problem that motivated the review; literature review performed through explicit methodology in regard to key words, search criteria, database, manual checking of references, data selected and reasons for selection, number of articles located, criteria for article selection and exclusion, classification of procedures of the literature, and synthesis of the review; description of the conclusions, limitations, and suggestions for future research.

The amount of data identified in the review should be synthesized with an explicit criterion, in a way that develops taxonomies or another conceptual classification of constructs, through the use of models, alternative conceptual structures or meta-theory ${ }^{(23)}$.

An IR requires a detailed description of the methodology used in its development, and the entire process should be carried out with a reflective attitude, so that the result produced can significantly contribute to the construction of knowledge and care practice ${ }^{(8,20)}$.

The search strategy should be formulated to recover the maximum number of eligible studies, with the use of a minimum of two or three search strategies ${ }^{(18)}$. Restricted searches should be justified, and small methodological inadequacies do not make the results unfeasible for all studies, but should be explained in the study ${ }^{(8)}$.

Five desirable and six undesirable attributes in the development of an IR, have been reported ${ }^{(15)}$ :

Desirable attributes: (a) The existence of a group of reviewers to review and synthesize the results; (b) Clarity and consistency in quality of the study, and use of definitions to specify the level of evidence; (c) Existence of a conceptual structure based on a model of research use; (d) Inclusion of tables containing clear, consistent, and critical information in regards to information relative to the applicability of the results; and (e) Representation of the studies in tables, in a way that distinguishes aspects of the results, which should be coherently separated to enable their practical application and communication with researchers recognized in the field under review ${ }^{(15)}$.

Undesirable attributes: (a) Premature conclusions with weak support of evidence; (b)Absence of a consistent focus, in terms of quality and strength of the evidence of the studies included; (c)No discussion of the implications for care practice; (d) Absence of tables to present the synthesis of data extracted from each study; (e) Lack of coherence in organization of results around applicable aspects, but distinctly separated from a concept; and (f) The inclusion of references that present similar or repeated information ${ }^{(15)}$.

Lack of rigor can generate similar but invalid results. Biases are generally reflected in inconsistencies in the selection of subjects, treatment of variables, study locations or contexts, and quality of the research method ${ }^{(8)}$. The systematized compliance with all stages is essential to guarantee the methodological rigor of an $\mathrm{IR}^{(7,13)}$.

Standards of methodological rigor should be followed and results should be clearly presented. Respect for these prerequisites is fundamental so that the reader can identify the characteristics of the studies included in the review ${ }^{(21)}$.

\section{IR stages and method}

There are similarities in the stages of development of an IR proposed by the different authors. As the conceptualization of the IR occurs, the first proposals served as a basis for subsequent ones. Each author emphasizes the importance or presents greater detailing in relation to some phase of the review.

A model, composed of five stages, served as the matrix for subsequent publications on the stages of development of the IR: formulation of the problem, data collection; evaluation of data; analysis and interpretation of data; and publication of $\operatorname{data}^{(9)}$. The method for developing the IR emphasizes the need to define and explain operational concepts $^{(9)}$. Another author also suggests five stages: formulation of the problem; literature search; evaluation of data; data analysis (to categorize the data); and presentation of the results ${ }^{(18)}$.

Considering that an operational definition has the potential to attribute a communicable meaning to a concept by specifying how the concept is applied, this can offer the reviewer freedom in the literature search and analysis. This implies dominion of the studied topic, and the capacity to integrate the research findings through these operational concepts.

Operational diversity can affect the results of the review in two ways: first, it is necessary to consider that the operational definitions chosen by the reviewers can vary. Two reviewers using the same definition in conceptual 
terms can employ different operational definitions or levels of abstraction. Every definition may contain operations that were excluded by the other, or the definition developed by one reviewer may contain that developed by the other. An evaluator can also encounter important concepts during the research that were initially not considered. The reviewer can define the same concept in different ways, and this phenomenon can occur with a certain frequency. Second, the diversity among studies on the same concept should be considered, which means that the reviewers can present variations in regard to treatment of data after it has been explored ${ }^{(9)}$.

Another model presents six stages for analysis of the articles: selection of the research question and hypotheses; selection of primary studies; presentation of the characteristics of the primary studies; analysis of primary studies; interpretation of the results; and writing or reporting on the review ${ }^{(8)}$. A model with seven stages to direct the IR has also been suggested: (a) introduction, justification and hypothesis; (b) sampling procedures; (c) measurements and operations; (d) general procedures; (e) analysis of data and results; (f) interpretations, limitations and implications; and (g) presentation of the review ${ }^{(12)}$.

The desired characteristics of the team responsible for an IR are clear ${ }^{(15)}$ :the team members should have sufficient interest and knowledge to develop an IR. Thus, Whittemore ${ }^{(18)}$ recommends the involvement of nurses with master degrees in the study, as they can be responsible for the extraction and translation of data for the other members of the group who have more limited research training. Further, this author highlights the importance of the interdisciplinary composition of the team of reviewers.

Evaluation of the studies included may be guided by questions that include interrogations in regard to the research question, reason, and purpose for obtaining responses to the question, questions already put forth in regards to the research topic, methodological appropriateness, inclusion of subjects, results desired, correspondence between the question of the review and data collected, and recommendation of new reviews ${ }^{(22)}$.

There is currently no gold standard for analysis of data that generally evaluates the methodology of primary studies ${ }^{(18)}$. The essential elements of the process of data analysis of an IR are: observe standards and themes, verify their plausibility, make comparisons and contrasts, discern common and uncommon standards, not consider particulars in general, observe relationships in the variability of data, identify intervening factors, and construct evidence according to a logical sequence ${ }^{(7)}$. The data from a study should be analyzed within a stratum that considers the different characteristics of the subjects, treatment of the variables, contextual variables, and the effects of the interactions between such variables ${ }^{(8)}$.

In regard to the presentation of results, three approaches are suggested: as a summary, through description of the findings with categories or themes; as an analysis, which, in addition to a description, contains a critical analysis of methods, results, and/or applicability in practice; and as a synthesis that includes the creation of new models and organizational structure for the research problem ${ }^{(18)}$.

The synthesis of an IR should be developed through the direction of new research, development of a taxonomy or attribution of another conceptual classification for the constructs, development of alternative models or conceptual approaches to base the synthesis process, and even through the development of a meta-theory ${ }^{(19)}$. Chart 5 indicates the phases of development of an IR, and the authors that recommend each item.

Chart 5 - Stages of development of an IR, and the authors who recommend them - São Paulo, 2013




Continuation

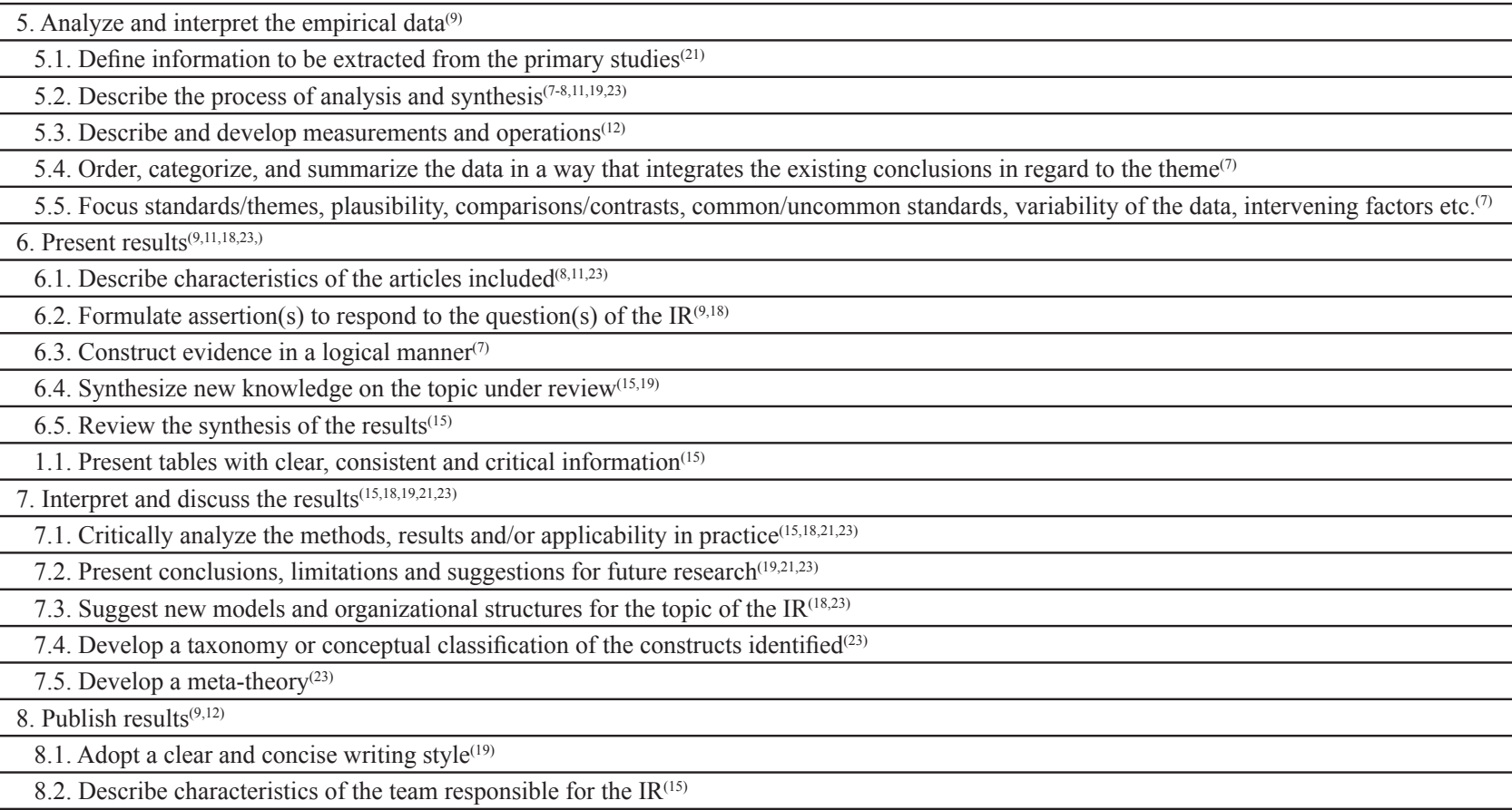

\section{Aspects that should be evaluated in the IR}

Different authors emphasize the need for systematic evaluation of the IR. Some only mention the more important topics that should be subject to evaluation, whereas others develop specific criteria to evaluate an IR.

An IR should be evaluated through the detailed demonstration or description of data collection, as well as variables considered, which should be registered on a notebook of codes ${ }^{(13)}$.

A checklist, comprising the proposal of the review, sampling methods, criteria for inclusion of studies, characteristics of the primary research, citation of authors' comments, critique of previous comments, presentation of the results of the primary research, method for analysis of results, discussion of methodological problems, a search for systematic influences, interpretation of results, and use of tables, was developed specifically to check if the stages developed in the IR are adequate ${ }^{(11)}$.

Three distinct checklists were developed: 1) to assess the methodological rigor of meta-analyses ${ }^{(15)} ; 2$ ) to evaluate the $I R^{(15)}$; and 3 ) to serve as a guide for the development of an IR ${ }^{(19)}$.

\section{DISCUSSION}

Here, we studied the IR method in nursing by performing an IR, which resulted in the selection of 17 publications, and permitted the identification and analysis of the concepts, the need for methodological rigor, and the stages for developing an IR configured to its specific methodology.
The concepts of IR refer to generalizing inferences ${ }^{(8,11-12)}$ summarizing and synthesizing accumulated knowledge ${ }^{(9-10,15,20)}$ and interrelating results from previous studies in a critical manner to produce new, integrated knowledge ${ }^{(7,13-14,18-18)}$. Thus, it is observed that the selected literature chronologically advances to a comprehensive conception in two senses, both in regard to previous studies examined by the IR, and to attaining new results from the IR.

This latter aspect is in regard to the unfolding and effects that an IR can have over the advancement of knowledge, and thus its expressive application in nursing, which is currently in a phase of consolidation as a field of knowledge, scientific discipline, and evidence-based practice ${ }^{(14)}$.

The other aspect of IR is its distinctive characteristic of including quantitative and qualitative primary studies, developed with different methodologies, in their different modalities, as well as theoretical studies ${ }^{(7,14,18,21-22)}$.This characteristic is not present in the pioneering works from the $1980 \mathrm{~s}^{(8-11)}$, but appears significantly in nursing, to analyze the contributions of IR to the construction of knowledge specific to the field of nursing ${ }^{(14)}$.

Another characteristic of IR that our analysis revealed was the definition of the research questions that comprise the first stage, which should be explained objectively based on a theoretical framework and clear concepts, as this will guide all subsequent stages of the review. Thus, a single IR can include various research questions or hypotheses.

The inclusion of studies with different methodologies, as well as different research questions and hypotheses, makes the design of IR complex and difficult to implement. Nevertheless, the results produced by IR comprise a broad range of products: production of new knowledge from the 
synthesis of the studies selected, including both empirical findings as well as conceptual and theoretical developments; identification of connections between different fields of knowledge and central themes of a specific field; identification of theoretical and methodological approaches with greater explanatory and comprehensive potential; and gaps in the studies, and the need for future research.

Almost all of the authors highlight the need for methodological rigor when conducing IR, in order for the results to represent effective contributions to the practice of evidence-based health care, and the construction and consolidation of theory. Rigor refers to the clear definition of the problem and hypotheses, careful selection of the studies, analysis of the studies selected by two independent reviewers, and detailed presentation of the results of the analysis in synthesized tables, if possible.

The need for methodological rigor when conducing an IR is stated in the publications selected, in two inter-related ways: description and analysis of the stages that should be followed, from initial formulation of the review through publication of the results ${ }^{(8-9,12,18) ;}$ and the review method that is included in the stages, but comprises those that directly affect the research methodology adopted: sampling, search strategies, inclusion and exclusion criteria, evaluation of the selected publications, and analysis of the publications included in the review, for production of original results.

\section{CONCLUSION}

The findings of this IR lead to the conclusion that IR in nursing is a type of review that contemplates the rigor of

\section{REFERENCES}

1. Grant MJ, Booth A. A typology of reviews: an analysis of 14 review types and associated methodologies. Health Info Libr J. 2009;26(2):91-108.

2. Watson J, Smith MC. Caring science and the science of unitary human beings: a trans-theoretical discourse for nursing knowledge development. J Adv Nurs. 2002;37(5):452-61.

3. Flemming K. The knowledge base for evidence-based nursing: a role for mixed methods research? ANS Adv Nurs Sci. 2007;30(1):41-51.

4. Lacerda RA, Egry EY, Fonseca RMGS, Lopes NA, Nunes BK, Batista $\mathrm{AO}$, et al. Evidence-based practices published in Brazil: identification and analysis studies about human health prevention. Rev Esc Enferm USP [Internet]. 2012 [cited 2013 Mar 25];46 (5):1237-47. Available from: http://www.scielo.br/pdf/ reeusp/v46n5/en_28.pdf

5. Weaver K, Olson JK. Understanding paradigms used for nursing research. J Adv Nurs. 2006;53(4):459-69. the method particular to scientific research. It also concludes that it:

- Consists of a method for bringing together and synthesizing the results of investigations, originally constructed from the fields of education and psychology;

- Allows the inclusion of various research questions or hypotheses in the same review;

- Absorbs the concerns of the field with theories that ground the practices of nursing care, and, in this sense, aggregates review of theories to the already known and traditional review of empirical studies;

- Accepts integration of research designs, including those from different paradigms of knowledge production, in order to solidify the complexity of nursing care, which involves integration of individual and contextual questions;

- Requires reviewers who are experts in the field, capable of critically synthesizing theory and empirical data within the same epistemological frame, in order to discern the potential of each contribution to health care.

Finally, we suggest that international organizations responsible for producing knowledge and guidelines in evidence-based health care build a recommendation manual; one that differentiates and defines the various types of literature reviews in health so that reviewers are able to use the review terminology in accordance with the objective of their investigations. Such an initiative would add consistency to reviews for their broadest and safest application in health, particularly in nursing.

6. Souza MT, Silva MD, Carvalho R. Integrative review: what is it? How to do it? Einstein (São Paulo). 2010;8(1):102-6.

7. Whittemore R, Knafl K. The integrative review: updated methodology. J Adv Nurs. 2005;52(5):546-53.

8. Jackson GB. Methods for integrative reviews. Rev Educ Res. 1980;50(3):438-60.

9. Cooper HM. Scientific guidelines for conducting integrative research reviews. Rev Educ Res. 1982;52(2):291-302.

10. Cooper HM. The integrative research review: a systematic approach. Beverly Hills: Sage; 1984.

11. Ganong LH. Integrative reviews of nursing research. Res Nurs Health. 1987;10(1):1-11.

12. Ellis MV. Conducting and reporting integrative research reviews: accumulating scientific knowledge. Couns Educ Superv. 1991;30(3):225-36. 
13. Broome ME. Integrative literature review for the development of concepts. In: Rodgers BL, Knafl KA. Concept development in nursing. Philadelphia: Saunders; 1993. p. 231-50.

14. Kirkevold M. Integrative nursing research: an important strategy to further the development of nursing science and nursing practice. J Adv Nurs. 1997;25(5):977-84.

15. Stetler CB, Morsi D, Rucki S, Broughton S, Corrigan B, Fitzgerald J, et al. Utilization-focused integrative reviews in a nursing service. Appl Nurs Res. 1998;11(4):195-206.

16. Beyea S, Nicoll LH. Writing an integrative review. AORN J. 1998;67(4):877-80.

17. Roman AR, Friedlander MR. Integrative research review applied to nursing. Cogitare Enferm. 1998;3(2):109-12.

18. Whittemore R. Combining evidence in nursing research: methods and implications. Nurs Res. 2005;54(1):56-62.

19. Torraco RJ. Writing integrative literature reviews: guidelines and examples. Hum Resour Dev Rev. 2005;4(3):356-67.

20. Russell CL. An overview of the integrative research review. Prog Transplant. 2005;15(1):8-13.

21. Mendes KDS, Silveira RCCP, Galvão CM. Revisão integrativa: método de pesquisa para a incorporação de evidências na saúde e na enfermagem. Texto Contexto Enferm. 2008;17(4):758-64.
22. Pompeo DA, Rossi LA, Galvão CM. Revisão integrativa: etapa inicial do processo de validação de diagnóstico de enfermagem. Acta Paul Enferm. 2009;22(4):434-8.

23. Carliner S. Workshop in conducting integrative literature reviews. In: IEEE International Professional Communication Conference; 2011 Oct 17-19; Cincinnati, OH, USA [Internet]. [cited Mar 25]. Available from: http://ieeexplore.ieee.org/ stamp/stamp.jsp?arnumber $=06087203$

24. Taveggia T. Resolving research controversy through empirical cumulation. Sociol Methods Res. 1974;2(4):395-407.

25. Cooper HM. Synthetizing research: a guide for literature reviews. 3rd ed. Thousand Oaks: Sage; 1998.

26. Jensen LA, Allen MN. Meta-synthesis of qualitative findings. Qual Health Res. 1996;6(4):553-60.

27. Kearney $\mathrm{MH}$. Levels and applications of qualitative research evidence. Res Nurs Health. 2001;24(2):145-53.

28. Paterson BL, Thorne BL, Canam C, Jillings C. Meta-study of qualitative health research: a practical guide to meta-analysis and meta-synthesis. Thousand Oaks: Sage; 2001.

29. Sandelowski M, Barroso J. Classifyng the findings in qualitative studies. Qual Health Res. 2003;13(7):905-23.

30. Sandelowski M, Docherty S, Emden C. Focus on qualitative methods. Qualitative metasynthesis: issues and techniques. Res Nurs Health. 1997;20(4):365-71. 